\title{
PEMERIKSAAN GETAH PARU KORBAN TENGGELAM YANG DIOTOPSI DI RSUP SANGLAH PERIODE JANUARI 2010 - NOVEMBER 2014
}

\author{
Nur Ilyana Jamaludin \\ Fakultas Kedokteran Universitas Udayana, Denpasar \\ (ilyana.jamaludin@yahoo.com)
}

\section{ABSTRAK}

Tenggelam adalah kegagalan respirasi primer karena masuknya cairan ke saluran pernapasan. Di dunia, setiap tahun dilaporkan sekitar 372.000 kasus kematian akibat tenggelam. Di Indonesia, Bali khususnya yang terkenal dengan wisata laut, banyak wisatawan yang tenggelam, terutama pada musim liburan. Diagnosis tenggelam dapat ditegakkan dengan pemeriksaan forensik yang meliputi pemeriksaan luar dan pemeriksaan dalam. Namun sampai saat ini, pemeriksaan mikroskopik getah paru untuk menemukan diatome masih merupakan gold standard. Penelitian ini bertujuan untuk mengetahui penggunaan dan manfaat pemeriksaan mikroskopik getah paru dalam mendiagnosis kematian dan benda asing yang sering ditemukan, penelitian dilakukan di Instalasi Kedokteran Forensik RSUP Sanglah. Ini adalah penelitian deskriptif retrospektif dengan menggunakan data sekunder yang diperoleh dari Instalasi Kedokteran Forensik RSUP Sanglah. Didapatkan 24 kasus mati tenggelam yang dilakukan pemeriksaan getah paru $(85,7 \%$ dari seluruh kasus mati tenggelam yang diautopsi). Ganggang hijau paling banyak ditemukan yaitu sebanyak $79,2 \%$, sedangkan diatome sebanyak $54,2 \%$.

Kata kunci: diatome, ganggang hijau, pemeriksaan getah paru, tenggelam

\section{ABSTRACT}

Drowning is caused by primary failure of respiration due to a large amount of water entering the respiratory tract. Each year, it is estimated around 372.000 of death cases reported due to drowning in the world. Bali, Indonesia that is well-known for sea tourism has reported numerous cases of foreigners drowning especially during holiday season. Diagnosis of drowning can be made by performing forensic examinations that cover external and internal examinations. However, up until now microscopic examination of lung secretion to find diatome has been the gold standard test to diagnose drowning. This research is aimed for the application and benefit of microscopic examination of lung secretion in drowning cases and types of foreign bodies that were commonly found during the examination at Sanglah General Hospital. The design of this research is descriptive retrospective by using secondary data obtained from Forensic Department, Sanglah General Hospital. There were 24 cases that performed microscopic examination of lung secretion $(85,7 \%$ of total drowning cases underwent autopsy).Green algae was the most commonly foreign body found which is $79,2 \%$ meanwhile diatome accounts for $54,2 \%$ from all cases.

Keywords: diatome, green algae, examination of lung secretion, drowning

\section{PENDAHULUAN}

Tenggelam merupakan suatu proses kegagalan respirasi primer karena masuknya cairan dalam jumlah yang banyak ke dalam saluran pernapasan sehingga menyebabkan asfiksia. ${ }^{1}$ Suatu kematian yang disebabkan oleh tenggelam masih merupakan suatu hal yang sulit didiagnosis di bidang ilmu forensik. ${ }^{2}$

Di dunia, setiap tahun dilaporkan sekitar 372.000 kasus kematian akibat tenggelam. Angka ini menempati urutan ke-3 kematian di dunia akibat cedera tidak disengaja., 3,5
Di Bali - Indonesia, yang terkenal dengan wisata laut, banyak wisatawan yang dilaporkan tenggelam, terutama saat musim liburan. ${ }^{6}$ Kasus yang dilaporkan lebih banyak laki-laki, karena lebih sering kontak dengan laut tanpa didampingi rekan, ataupun dalam keadaan dibawah pengaruh alkohol saat berenang, menyelam, dan berselancar. ${ }^{5,7}$

Diagnosis tenggelam dapat ditegakkan dengan mempertimbangkan hasil pemeriksaan forensik yang meliputi pemeriksaan luar dan pemeriksaan dalam. ${ }^{2,5,7}$ Pemeriksaan makroskopik yang merupakan bagian dari pemeriksaan dalam biasanya dilakukan pada saluran 
pernapasan, kemudian dicari adanya perubahanperubahan yang terjadi secara mikroskopik. ${ }^{7}$

Sampai saat ini, pemeriksaan diatome merupakan pemeriksaan gold standard untuk menegakkan diagnosis kematian akibat tenggelam. Namun, pemeriksaan ini masih memiliki kontroversi karena diatome tidak dapat selalu ditemukan pada pemeriksaan getah paru. ${ }^{7} \mathrm{Hal}$ ini dapat terjadi pada kasus tenggelam yang atipikal seperti pada tipe dry drowning, faktor iklim yang mengganggu, prosedur dan penggunaan bahan kimia yang bersifat merusak dan menghancur diatome serta bisa juga karena terjadinya polusi air laut atau sungai. ${ }^{7,8}$

Penelitian ini bertujuan untuk mengetahui aplikasi dan manfaat pemeriksaan getah paru dalam mendiagnosis kasus kematian akibat tenggelam di Instalasi Kedokteran Forensik, RSUP Sanglah dan mengetahui benda asing yang sering ditemukan dalam pemeriksaan mikroskopik tersebut.

\section{METODE PENELITIAN}

Penelitian ini menggunakan desain deskriptif retrospektif dengan menggunakan hasil laporan autopsi yang diperoleh di Instalasi Kedokteran Forensik, RSUP Sanglah. Sampel yang diambil yaitu data kasus mati tenggelam yang dilakukan autopsi dari Januari 2010 sampai November 2014 dengan kriteria inklusi kasus mati tenggelam yang dilakukan pemeriksaan getah paru di Instalasi Kedokteran Forensik, RSUP Sanglah. Variabel lain yang akan diteliti antara lain adalah jenis kelamin dan hasil pemeriksaan getah paru.

\section{HASIL PENELITIAN}

Tabel 1. Distribusi kasus tenggelam yang dilakukan autopsi berdasarkan jenis kelamin

\begin{tabular}{ccc}
\hline Jenis Kelamin & Jumlah Kasus & $\%$ \\
\hline Laki-laki & 24 & 85,7 \\
Perempuan & 4 & 14,3 \\
\hline Total & 28 & 100
\end{tabular}

Berdasarkan dari data distribusi kasus tenggelam yang dilakukan autopsi mengikut jenis kelamin, didapatkan bahwa laki-laki lebih banyak meninggal akibat tenggelam yaitu sebanyak 24 kasus $(85,7 \%)$ dibandingkan perempuan hanya berjumlah 4 kasus $(14,3 \%)$.

Dari keseluruhan sampel tersebut, 24 kasus diantaranya dilakukan pemeriksaan mikroskopik getah paru $(85,7 \%)$, sedangkan 4 kasus lain tidak dilakukan $(14,3 \%)$. Ditemukan $87,5 \%$ dari keseluruhan kasus tenggelam yang dilakukan pemeriksaan getah paru memberikan hasil positif dengan adanya penemuan benda asing seperti ganggang hijau, diatome, pasir dan serat tumbuhan pada pemeriksaan mikroskopik tersebut (21 dari 24 kasus), sedangkan 3 kasus lain memberikan hasil yang negatif $(12,5 \%)$.

Tabel 2. Pemeriksaan getah paru pada kasus tenggelam yang dilakukan autopsi

\begin{tabular}{ccc}
\hline $\begin{array}{c}\text { Pemeriksaan Getah } \\
\text { Paru }\end{array}$ & Jumlah Kasus & $\%$ \\
\hline Dilakukan & 24 & 85,7 \\
Tidak dilakukan & 4 & 14,3 \\
\hline Total & 28 & 100
\end{tabular}

Tabel 3. Hasil pemeriksaan getah paru pada kasus tenggelam yang dilakukan autopsi

\begin{tabular}{ccc}
\hline Hasil & Jumlah Kasus & $\%$ \\
\hline Positif & 21 & 87,5 \\
Negatif & 3 & 12,5 \\
\hline Total & 24 & 100
\end{tabular}

Tabel 4. Benda asing yang ditemukan pada pemeriksaan getah paru pada kasus tenggelam yang dilakukan autopsi

\begin{tabular}{cccc}
\hline No. & $\begin{array}{c}\text { Benda Asing } \\
\text { yang Ditemukan }\end{array}$ & $\begin{array}{c}\text { Jumlah } \\
\text { Kasus }\end{array}$ & $\%$ \\
\hline 1 & Ganggang hijau & 19 & 79,2 \\
2 & Diatome & 13 & 54,2 \\
3 & Pasir & 4 & 16,7 \\
4 & Serat tumbuhan & 4 & 16,7 \\
5 & $\begin{array}{c}\text { Kristal Charcot } \\
\text { Leyden }\end{array}$ & 3 & 12,5 \\
\hline
\end{tabular}

\section{PEMBAHASAN}

Tenggelam merupakan suatu proses yang disebabkan oleh kegagalan respirasi primer karena masuknya cairan yang cukup ke dalam saluran pernapasan. ${ }^{1}$ Menurut World Health Organization (WHO), setiap tahun sekitar 372.000 atau lebih kasus kematian yang dilaporkan akibat tenggelam di seluruh dunia. ${ }^{3}$ Bali, Indonesia yang terkenal dengan wisata laut, banyak terjadi kasus wisatawan yang tenggelam terutama pada saat musim liburan. ${ }^{6}$ Penelitian ini dijalankan di Instalasi Kedokteran Forensik, RSUP Sanglah yang bertujuan untuk mengetahui aplikasi dan manfaat pemeriksaan mikroskopik getah paru dalam menegakkan diagnosis mati akibat tenggelam.

Berdasarkan dari data distribusi kasus tenggelam yang dilakukan autopsi mengikut jenis kelamin, didapatkan bahwa laki-laki lebih banyak meninggal akibat tenggelam yaitu sebanyak 24 kasus $(85,7 \%)$ dibandingkan perempuan yang berjumlah 4 
kasus (14,3\%). Hasil ini disokong oleh WHO dan Centers for Disease Control and Prevention (CDC) yang menyatakan bahwa laki-laki lebih sering mengalami kejadian tenggelam dibandingkan perempuan. ${ }^{3,4,5}$ Penelitian yang dilakukan oleh Fitricia R., Rifino A.W., dkk pada tahun 2010 dan 2012 juga mendapatkan hasil yang serupa..$^{9,10} \mathrm{Hal}$ ini dapat dijelaskan karena laki-laki lebih sering mengalami paparan dengan air seperti berenang sendiri, mengkonsumsi alkohol sebelum berenang dan kegiatan hobi seperti menyelam dan meluncur di laut. ${ }^{5}$

Didapatkan sebanyak 28 kasus mati tenggelam yang dilakukan autopsi pada periode Januari 2010 November 2014 di Instalasi Kedokteran Forensik, RSUP Sanglah. 24 kasus darinya dilakukan pemeriksaan mikroskopik getah paru untuk menegakkan diagnosis mati tenggelam $(85,7 \%)$, sedangkan 4 kasus lain tidak dilakukan (14,3\%) karena dari pemeriksaan makroskopik sudah ditemukan adanya benda asing dalam saluran pernapasan seperti pasir, batu kerikil bahkan lumpur yang masuk pada saat korban berusaha untuk bernapas di dalam air., ${ }^{1,7}$

$87,5 \%$ dari keseluruhan kasus tenggelam yang dilakukan pemeriksaan getah paru memberikan hasil positif dengan adanya penemuan benda asing seperti ganggang hijau, diatome, pasir dan serat tumbuhan pada pemeriksaan mikroskopik tersebut (21 dari 24 kasus), sedangkan 3 kasus lain memberikan hasil yang negatif $(12,5 \%)$. Hasil pemeriksaan getah paru yang negatif dapat disebabkan oleh sedikitnya air yang masuk ke dalam saluran pernafasan seperti pada dry drowning atau air yang tidak mengandung benda asing. ${ }^{1,7} \mathrm{Hal}$ ini sesuai dengan teori yang menyatakan bahwa benda asing yang ditemukan pada saluran pernapasan akan bersesuaian dengan benda asing yang ditemukan pada air tempat jenasah itu tenggelam. ${ }^{7}$

Sementara itu, hasil pemeriksaan mikroskopik getah paru menunjukkan bahwa ganggang hijau paling sering ditemukan, 79,2\% dari keseluruhan kasus, yang diikuti oleh diatome $(54,2 \%)$, pasir dan serat tumbuhan yang masing-masingnya sebesar $16,7 \%$. Walaupun penemuan diatome merupakan pemeriksaan gold standard untuk mendiagnosis tenggelam, pemeriksaan ini masih memiliki kontroversi karena diatome tidak dapat selalu ditemukan pada pemeriksaan getah paru. ${ }^{7}$ Hal ini dapat terjadi pada kasus tenggelam seperti pada tipe dry drowning, faktor iklim yang mengganggu, prosedur dan penggunaan bahan kimia yang bersifat merusak dan menghancur diatome dan bisa juga karena terjadinya polusi air laut atau sungai. ${ }^{5,8}$

Teori yang mengatakan bahwa mikroorganisme dalam air dapat masuk ke dalam saluran pernapasan selain diatome dapat dibuktikan dengan penemuan ganggang hijau pada pemeriksaan paru (79,2\% dari seluruh kasus). ${ }^{1,7}$

\section{SIMPULAN}

Penelitian yang dilakukan dengan mengambil data sekunder di Instalasi Kedokteran Forensik RSUP Sanglah ini dapat menyimpulkan beberapa hal:

1. Insiden kematian akibat tenggelam pada lakilaki $(85,7 \%)$ lebih lebih tinggi berbanding perempuan (14,3\%).

2. Pemeriksaan mikroskopik getah paru dilakukan pada 85,7\% kasus dari total kasus tenggelam yang dilakukan autopsi.

3. Pemeriksaan mikroskopik getah paru masih bermanfaat dalam menegakkan diagnosis tenggelam pada jenazah yang diduga mati tenggelam.

4. Benda asing yang ditemukan dalam pemeriksaan mikroskopik getah paru antara lain ganggang hijau 79,2\%, diatome 54,2\%, pasir $16,7 \%$, serat tumbuhan $16,7 \%$ dan Kristal Charcot Leyden $12,5 \%$.

\section{SARAN}

Berdasarkan dari hasil yang diperoleh dalam penelitian ini, disarankan agar pemeriksaan mikroskopik getah paru dilakukan pada semua kasus yang diduga mati tenggelam. Hal ini bertujuan untuk menegakkan diagnosis tenggelam dengan lebih pasti.

Juga disarankan agar dilakukan penelitianpenelitian lainnya mengenai apa saja yang dapat dipergunakan sebagai penanda bahwa suatu kematian diakibatkan oleh tenggelam dengan menggunakan metode yang sederhana seperti pada pemeriksaan getah paru. Hal ini dikarenakan pada satu jenazah yang diperiksa dengan pemeriksaan getah paru ternyata tidak semua ditemukan adanya benda asing seperti ganggang hijau, diatome, pasir dan lain-lain karena dipengaruhi oleh berbagai faktor seperti lokasi terjadinya tenggelam, mekanisme tenggelam, jumlah air yang masuk ke dalam paru, dan lain-lain.

\section{DAFTAR PUSTAKA}

1. Idries AM. Pedoman Ilmu Kedokteran Forensik. Ed I. Jakarta: Binarupa Aksara; 1997.

2. Farrugia A, Ludes B. Diagnostic of Drowning in Forensic Medicine. Prof. Duarte Nuno Vieira, Editor. Forensic Medicine - From Old Problem to New Challenges; 2011 [cited 2014 Dec]. Available from: http://cdn.intechopen.com/pdfs/19161/InTec $\underline{\mathrm{h}}$ Diagnostic of drowning in forensic medicin e.pdf

3. World Health Organization. Drowning. Fact sheet N³47; 2014 [cited 2014 Dec 11]. Available from: 
http://www.who.int/mediacentre/factsheets /fs347/en/

4. Centers for Disease Control and Prevention. Unintentional Drowning: Get the Facts. CDC; 2014 [cited 2014 Dec 11]. Available from http://www.cdc.gov/homeandrecreationalsaf ety/water-safety/waterinjuries-

factsheet.html

5. Cantwell GP. Drowning. Verive MJ, Shoff WH, Alcock J, editors. Medscape reference; 2014 [cited 2014 Dec 11]. Available from: http://emedicine.medscape.com/article/7727 53-overview

6. Situmorang N. Pendidikan untuk Kesejahteraan Nelayan. Kementerian Kelautan dan Perikanan Republik Indonesia; 2012. Available from http://www.kkp.go.id/index.php/arsip/c/723 3/Pendidikan-untuk-Kesejahteraan-Nelayan/
7. Piette MHA, De Letter EA. Drowning: Still a difficult autopsy diagnosis. Forensic Science International. 2006; 163: 1-9.

8. Law YY, Jayaprakash PT. Prevalence of diatom frustules in non-vegetarian foodstuffs and it's implications in interpreting identification of diatom frustules in drowning cases. Forensic Science International. 2007; 170: 1 - 7.

9. Fitricia R. Tanda intravital yang ditemukan pada kasus tenggelam di departemen kedokteran forensik FK USU RSUP H. Adam Malik/ RSUD Pirngadi Medan pada bulan Januari 2007 - Desember 2009. Medan: FK USU; 2010.

10. Rifino AW., Johannis FM., Djemi CT. Gambaran temuan autopsi kasus tenggelam di BLU RSU Prof. Dr. R. D. Kandou Manado periode Januari 2007 - Desember 2011. Manado: FK USRAT; 2012. 